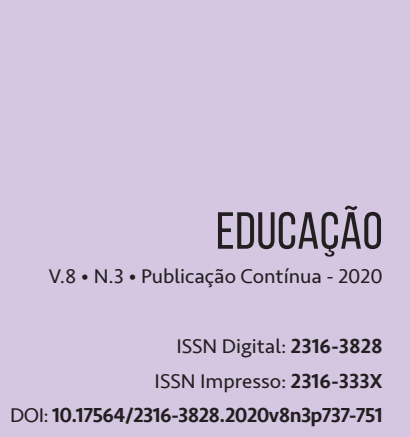

\section{NOVO MAIS EDUCAÇÃO: UM OLHAR DA PSICOLOGIA ESCOLAR EDUCACIONAL PARA AS POLÍTICAS PÚBLICAS}

\section{NOVO MAIS EDUCAC̄̃̃O: UNA MRADA DE LA PSICOLOGÍA ESCOLAR Y EDUCATIVA ALAS POLIITICAS PÚBLICAS}

\section{NOVO MAIS EDUCAÇAOO: A LOOK FROM SCHOOL AND EDUCATIONAL PSYCHOLOGY TO PUBLLC POLLCES}

Bárbara Maria Costa Silva ${ }^{1}$ Silvia Maria Cintra da Silva ${ }^{2}$

\section{RESUMO}

A Psicologia Escolar e Educacional vem conquistando seu espaço e seu reconhecimento ao longo dos anos, rompendo com barreiras importantes na direção de uma ação comprometida com uma educação a que todos tenham acesso. As Políticas Públicas Educacionais são responsáveis por garantir o direito à educação de todos e, por isto, se faz importante a atuação do psicólogo frente à elaboração e implementação de tais políticas. Um dos programas nacionais voltados à expansão da jornada escolar é o Programa Novo Mais Educação, do Ministério da Educação. Assim, esta pesquisa tem como objetivo analisar a implementação do Programa Novo Mais Educação à luz da Psicologia Escolar Crítica. Para a realização da pesquisa, de cunho qualitativo, foram efetuadas observações das atividades e entrevistas com a Articuladora do Programa, Monitor de Língua Portuguesa, Monitor de Matemática, Facilitador de dança, Facilitador de capoeira e Facilitador de artesanato. As entrevistas foram transcritas e analisadas a partir da vertente da Psicologia Escolar Crítica. Foram encontradas muitas contradições entre as ações implementadas para a efetivação do programa e os objetivos presentes nos documentos oficiais que pretendiam "erradicar o fracasso escolar", além de um discurso preconceituoso sobre as classes mais vulneráveis. As Políticas Educacionais precisam ser repensadas e elaboradas de forma coletiva, com a participação dos diferentes atores envolvidos com as questões educacionais e com a parceria da Psicologia Escolar; ademais, é imprescindível que os governantes incluam em suas políticas de governo investimentos condizentes com as reais necessidades uma educação de qualidade em nosso país. 


\section{PALAVRAS-CHAVE}

psicologia escolar, educação, políticas públicas

\section{ABSTRACTO}

La Psicología Escolar y de la Educación sigue ganando espacio y reconocimiento a lo largo de los años, rompiendo importantes barreras hacia una acción comprometida con una educación a la que todos tienen acceso. Las Políticas Públicas Educativas son responsables de garantizar el derecho a la educación de todos y, por ello, el papel del psicólogo en el desarrollo e implementación de dichas políticas es importante. Uno de los programas nacionales destinados a ampliar la jornada escolar es el Programa Novo Mais Educação, del Ministerio de Educación. Así, esta investigación tiene como objetivo analizar la implementación del Programa Novo Mais Educação a la luz de la Psicología Crítica Escolar. Para realizar la investigación, de carácter cualitativo, se realizaron observaciones de las actividades y entrevistas con el Coordinador del Programa, Monitor de Lengua Portuguesa, Monitor de Matemáticas, Facilitador de Danza, Facilitador de Capoeira y Facilitador de Artesanía. Las entrevistas fueron transcritas y analizadas desde la perspectiva de la Psicología Crítica Escolar. Se encontraron muchas contradicciones entre las acciones implementadas para llevar a cabo el programa y los objetivos presentes en los documentos oficiales que pretendían "erradicar el fracaso escolar", además de un discurso prejuicioso sobre las clases más vulnerables. Es necesario repensar y elaborar las Políticas Educativas de manera colectiva, con la participación de los diferentes actores involucrados en la temática educativa y con la alianza de Psicología Escolar; Además, es fundamental que los funcionarios de gobierno incluyan en sus políticas de gobierno inversiones acordes con las necesidades reales de educación de calidad en nuestro país.

\section{PALAVRAS-CHAVE}

psicología escolar, educación, políticas públicas

\section{ABSTRACT}

School and Educational Psychology has been gaining its space and recognition over the years, breaking down important barriers towards an action committed to an education that everyone has access to. Public Educational Policies are responsible for guaranteeing the right to education for all and, for this reason, the role of the psychologist in the development and implementation of such policies is 
important. One of the national programs aimed at expanding the school day is the Novo Mais Educação Program, from the Ministry of Education. Thus, this research aims to analyze the implementation of the Novo Mais Educação Program in the light of Critical School Psychology. To carry out the research, of a qualitative nature, observations were made of the activities and interviews with the Program Coordinator, Portuguese Language Monitor, Mathematics Monitor, Dance Facilitator, Capoeira Facilitator and Craft Facilitator. The interviews were transcribed and analyzed from the perspective of Critical School Psychology. Many contradictions were found between the actions implemented to carry out the program and the objectives present in the official documents that intended to "eradicate school failure", in addition to a prejudiced discourse about the most vulnerable classes. Educational Policies need to be rethought and elaborated collectively, with the participation of different actors involved with educational issues and with the partnership of School Psychology; in addition, it is essential that government officials include in their government policies investments in line with the real needs of quality education in our country.

\section{PALAVRAS-CHAVE}

school psychology, education, public policy

\section{INTRODUCÇÃO}

Sempre que o nosso casaco se rasga vocês vêm correndo dizer: assim não pode ser; isso vai acabar, custe o que custar! Cheios de fé vão aos senhores enquanto nós, cheios de frio, aguardamos. E ao voltar, sempre triunfantes, nos mostram o que por nós conquistam: Um pequeno remendo. (BRECHT, 1990, p 179.)

O surgimento da Psicologia no Brasil teve como campo fértil o contexto educacional, sendo as escolas os primeiros lugares de aplicação prática desse conhecimento, em que foram desenvolvendo-se os saberes da Psicologia Escolar e Educacional. De acordo com Barbosa (2012), podemos considerar que a Psicologia Educacional refere-se à produção teórica dos saberes sobre o processo educativo e a Psicologia Escolar à prática do psicólogo nos variados contextos educativos. As práticas eram voltadas para as populações mais vulneráveis, embora se baseasse em ideias preconceituosas, conservadoras, excludentes e que atendiam aos interesses de uma classe dominante do sistema capitalista (ANTUNES, 2003; 2014; PATTO, 2007).

A atuação e o ensino dos profissionais da Psicologia se baseavam em um modelo médico, com a aplicação de testes de aptidão e um atendimento individualizante, que proporcionavam uma interpretação superficial sobre os processos educativos, colaborando para a manutenção de uma educação desigual, que colocava a culpa na criança e em suas relações familiares, muitas vezes excluindo-as deste espaço, desconsiderando as relações sociais e pedagógicas constitutivas do contexto escolar (ANTUNES, 2003, 2014). 
A crítica à Psicologia Escolar e Educacional surgiu de um movimento geral de crítica à Psicologia como ciência e profissão. Buscava-se uma reformulação das concepções teóricas e práticas sobre a complexidade do psiquismo que fossem coerentes com a realidade social e econômica do país, pensando em ações concretas que se comprometessem com os problemas da população brasileira, principalmente das classes populares (ANTUNES, 2014).

Com essa onda de críticas diante da atuação dos psicólogos, na década de 1990 começa-se a pensar e a buscar práticas que chegassem às classes mais carentes da sociedade, respondendo a demandas sociais. Tira-se de campo a ideia de problemas de aprendizagem, baseados em ideias biologicistas e individualizantes, focando-se nas concepções de fracasso escolar e queixas escolares. De acordo com Souza (2007), entende-se por queixa escolar o resultado das relações entre a criança ou adolescente, sua família e sua escola, que se manifesta durante o processo de escolarização, sendo que a queixa escolar surge e se sustenta no ambiente escolar.

A partir do avanço do neoliberalismo, nos anos 1990, o Brasil vivia um momento histórico em que as políticas eram voltadas para o desenvolvimento econômico favorável ao capital internacional, o qual pretendia tirar o país da situação de subdesenvolvimento, avançando na sua industrialização, com um crescimento urbano acelerado. As Políticas Públicas eram assistencialistas e/ ou tecnocratas, atendendo ao modelo de desenvolvimento industrial; por exemplo, exigiam que a educação atingisse um nível de alfabetização imposto pelas demandas desenvolvimentistas, sem considerar a realidade social, como a crescente urbanização.

Assim, os movimentos pela democratização e lutas por direitos foram se fortalecendo devido às mazelas sociais, como mortalidade infantil, crianças e adolescentes em situação de rua, epidemias, precárias condições de moradias. Essas lutas deram origem à criação do Sistema Único de Saúde (SUS), ao Estatuto da Criança e do Adolescente (ECA) e inclusão dos direitos sociais na Constituição de 1988 (GONÇALVES, 2014).

Em 1990 foi realizada a Conferência Mundial de educação para Todos, em Jomtein, na Tailândia, onde foram construídas as Políticas Educacionais muito significativas, financiada pela Organização das Nações Unidas para a Educação, a Ciência e a Cultura (UNESCO), o Fundo das Nações Unidas para a Infância (UNICEF), o Programa das Nações Unidas para o Desenvolvimento (PNUD) e o Banco Mundial (BM), contou com a participação de 155 países (ZIBETTI; PACÍFICO; TAMBORIL, 2016).

Com o Compromisso Todos pela Educação, a função da escola sofreu importantes transformações, colocou em segundo plano a transmissão dos conhecimentos produzidos pela humanidade ao longo da história, priorizou um ensino baseado na lógica do mercado, seguiu os princípios neoliberais, como autonomia, flexibilidade, descentralização, desenvolvendo "competências e habilidades" necessárias para o mercado de trabalho, além de assumir outras responsabilidades sociais que antes eram de setores como a Assistência Social, Defesa Social, Saúde e outros (DIGIOVANNI, 2016; SAVIANI, 2018; SILVA, 2013).

Foi diante desse cenário, juntamente com as críticas ao compromisso da Psicologia, que se iniciaram as reflexões sobre a relação da Psicologia com as Políticas Públicas e, neste sentido, como essa área de conhecimento, comprometida com as demandas sociais, poderia contribuir para as elaborações e implementações de políticas que garantissem os direitos dos cidadãos. No bojo de tais 
transformações, a escola também passa a sofrer várias reformas oriundas das Políticas Públicas Educacionais, que pretendiam levar a educação para todos.

Assim, com a ascensão da Psicologia Escolar em uma vertente crítica, que entende o contexto escolar em suas relações cotidianas constituída por alunos, professores, gestores, funcionários, famílias, Estado, bairros e demais grupos relacionados à esfera educativa, deslocando o eixo de análise do indivíduo para o interior da escola e suas relações, consideramos que a implementação de Políticas Públicas deve ser coerente com esse cenário, propondo ações pedagógicas, institucionais e políticas (SOUZA, 2010; 2014).

Com o avanço do neoliberalismo, as políticas sociais são analisadas a partir da relação custo-benefício, sendo consideradas como um gasto em vários países com alto índice de desigualdade social. Nesse cenário, a escola assume outras funções como proteção social e promoção de justiça social, assumindo responsabilidades e atribuições da Assistência Social, Defesa Social e Saúde, atendendo à lógica do mercado. Sendo assim, os programas e projetos sociais passam a proliferar no terreno escolar, como é visto nas ações dos governos anteriores, Programa Bolsa Escola do governo FHC e Programa Bolsa Família do governo Lula, vigentes até hoje (OLIVEIRA; DUARTE, 2005; SAVIANI, 2004; SILVA, 2013).

Para a proteção e promoção social de alunos de áreas de maior vulnerabilidade social, são aplicados programas de ampliação da jornada escolar, com atividades socioeducativas no contra turno (OLIVEIRA; DUARTE, 2005; SILVA, 2013). Essa medida é encontrada no Programa Novo Mais Educação, sendo atualmente o principal programa de educação integral do Ensino Fundamental proposto pelo Ministério da Educação.

Leclerc e Moll (2012) definem Educação Integral como ações educativas que abrangem diversas dimensões da formação do indivíduo; quando tal modalidade se refere à educação escolar apresenta uma ligação entre as ações intencionais da instituição e a vida em sentido amplo. Já a Educação em Tempo Integral se refere, no sentido restrito, à organização do tempo de permanência dos estudantes no ambiente escolar, sendo denominada, também, como ampliação da jornada escolar; em sentido amplo, amplia-se o tempo de permanência na escola quando há necessidade de reinventar o cotidiano escolar.

O Programa Novo Mais Educação (PNME), criado no Governo Temer pela Portaria do Ministério da Educação (MEC) n 1.144/2016 e regido pela Resolução FNDE nº 17/2017, é uma reformulação do antigo Programa Mais Educação, criado por meio da Portaria Interministerial $n^{0} 17$, no Governo Lula. O PNME é uma estratégia do Ministério da Educação que tem como objetivo melhorar a aprendizagem em Língua Portuguesa e Matemática no Ensino Fundamental, por meio da ampliação da jornada escolar de crianças e adolescentes, otimizando o tempo de permanência dos estudantes na escola.

Além destes objetivos, o programa pretende reduzir o abandono, a reprovação, a distorção idade/ano e promover melhorias nos resultados de aprendizagem do $3^{\circ}$ ao $9^{\circ}$ ano do Ensino Fundamental. Podem participar do programa as escolas que receberam recursos do Plano Dinheiro Direto na Escola (PDDE) Educação Integral entre 2004 e 2016; escolas que apresentam Índice de Nível Socioeconômico baixo ou muito baixo segundo o Instituto Nacional de Estudos e Pesquisas Educacionais Anísio Teixeira (INEP) e as escolas que obtiveram baixo desempenho no Índice de Desenvolvimento da Educação (IDEB).

O Programa Novo Mais Educação contém oito diretrizes, são elas: integrar o Programa à política educacional da rede de ensino; integrar as atividades ao projeto político pedagógico da escola; 
priorizar os alunos e as escolas de regiões mais vulneráveis; priorizar os alunos com maiores dificuldades de aprendizagem; priorizar as escolas com piores indicadores educacionais; pactuar metas entre o MEC, os entes federados e as escolas participantes; monitorar e avaliar periodicamente a execução e os resultados do Programa, e estimular a cooperação entre União, Estados, Distrito Federal e Municípios (BRASIL, 2016).

A expansão da carga horária pode ser de 5 ou 15 horas. As escolas que optarem por cinco horas semanais devem realizar duas horas e meia de acompanhamento pedagógico da Língua Portuguesa e duas horas e meia de acompanhamento pedagógico de Matemática. As que optarem pela jornada de 15 horas devem destinar quatro horas de acompanhamento pedagógico da Língua Portuguesa e mais quatro horas de acompanhamento pedagógico de Matemática, e as sete horas restantes deveriam ser divididas em três atividades de sua escolha, disponíveis no Sistema PDDE Interativo.

\section{METODOLOGIA}

Este trabalho é uma pesquisa qualitativa acerca das relações entre a Psicologia Escolar e Educacional e as Políticas Públicas, mais especificamente acerca do Programa Novo Mais Educação, pautado pelas contribuições teóricas da Psicologia Escolar em uma vertente Crítica, sendo o objetivo principal analisar a implementação do Programa Novo Mais Educação à luz da Psicologia Escolar Crítica.

A pesquisa foi aprovada pelo Comitê de Ética da Universidade Federal de Uberlândia (UFU), Comitê de Ética em Pesquisa (CAAE) 89858818.4.0000.5152, e todos os participantes assinaram um Termo de Consentimento Livre e Esclarecido, explicando os objetivos da pesquisa e resguardando-os no que tange à confidencialidade, anonimato e sigilo dos dados construídos. Considerando o objetivo da pesquisa, utilizamos como critérios para a escolha da escola na implementação do Programa: que fosse localizada em um bairro periférico e que tivesse optado por ampliação da jornada escolar em 15 horas semanais. A escola selecionada, além dos acompanhamentos pedagógicos em Língua Portuguesa e em Matemática, obrigatórios, optou pelas atividades complementares de dança, capoeira e artesanato.

Para a elaboração dos materiais empíricos, foram realizadas entrevistas com a Articuladora do Programa, com os Monitores de Língua Portuguesa e Matemática, e com os Facilitadores de dança, artesanato e capoeira. Para a entrevista semiestruturada, a pesquisadora guiou-se por um roteiro com perguntas orientadoras, mas que permitiu aos entrevistados falarem abertamente sobre os tópicos destacados.

As entrevistas foram gravadas em áudio e transcritas. Na pesquisa qualitativa, o mais importante é a qualidade dos conhecimentos produzidos pela investigação e não há preocupação com a quantidade de participantes. Também foram realizadas observações na instituição por um período de três meses. A pesquisadora foi à escola em diferentes dias e horários, com o intuito de observar todas as atividades em todas as turmas, mantendo relatórios diários de cada visita. 


\section{RESULTADOSE DISCUSSÃO}

Após as entrevistas e observações realizadas, estas foram analisadas a partir dos objetivos do Programa, contidos nos documentos oficiais em contraposição com a realidade do dia a dia de sua implementação. Separamos os pontos mais destacados pelos participantes que possibilitassem compreender como o programa foi estruturado a fim de cumprir com seus objetivos principais, que são:

Melhorar a aprendizagem em Língua Portuguesa e Matemática no Ensino Fundamental;

Reduzir o abandono, a reprovação, a distorção idade/ano e promover melhorias nos resultados de aprendizagem do Ensino Fundamental, além de cumprir algumas de suas oito diretrizes, que são: integrar o Programa à política educacional da rede de ensino;

Integrar as atividades ao projeto político pedagógico da escola;

Priorizar os alunos e as escolas de regiões mais vulneráveis;

Priorizar os alunos com maiores dificuldades de aprendizagem;

Priorizar as escolas com piores indicadores educacionais;

Pactuar metas entre o MEC, os entes federados e as escolas participantes;

Monitorar e avaliar periodicamente a execução e os resultados do Programa, e estimular a cooperação entre União, Estados, Distrito Federal e Municípios (BRASIL, 2016).

Como afirma Souza (2014, p. 20), "Entender as políticas públicas é compreender como os educadores, alunos e gestores vivenciam sua implementação e participam de sua concepção". A Psicologia Escolar Crítica entende que o processo de escolarização é constituído pelas relações estabelecidas com toda a rede que compõe a escola: a direção, a equipe administrativa, os professores, os pais, a comunidade e os alunos, considerada a partir de suas raízes históricas, sociais e culturais. Sendo assim, para a implementação de Políticas Públicas é necessário pensar a escola em seus processos diários, analisando como estas políticas são apropriadas se transformando em prática pedagógica, constituindo de fato aquele espaço e seus atores.

Por entender que o fracasso escolar é produzido pelos processos de escolarização e pelas Políticas Públicas Educacionais que constituem esse espaço é que surge o interesse de analisar o dia a dia do Programa Novo Mais Educação; para compreender os seus bastidores, os discursos oficiais dos documentos que respaldam sua criação e execução, a materialização das práticas educativas e a participação de quem a produz.

A pesquisa se baseou em observações das ações do programa feitas pela pesquisadora; por entrevistas realizadas com a Articuladora do programa, os Monitores de acompanhamento pedagógico e os Facilitadores das atividades de livre escolha. Neste artigo fizemos um recorte na análise, destacando quatro objetivos do Programa: a melhoria na aprendizagem em Língua Portuguesa e Matemática; a erradicação do fracasso escolar, a partir da redução do abandono, a reprovação, e a distorção idade/ série; a priorização de alunos das camadas mais vulneráveis da sociedade e que apresentam dificuldades de aprendizagem; e a integração do Programa no projeto político e pedagógico da escola.

O Programa Novo Mais Educação traz como objetivo principal a melhoria na aprendizagem em Língua Portuguesa e Matemática, por meio da ampliação da jornada escolar e consequentemente a melhoria nos resultados de aprendizagem do $3^{\circ}$ ao $9^{\circ}$ ano do Ensino Fundamental. O PNME deixa cla- 
ro que o acompanhamento pedagógico ganha centralidade no programa - ressaltando que as escolas podem aderir somente às 5 horas - pois é por dele que ocorrerá o enfrentamento das dificuldades de aprendizagem e superação do fracasso escolar.

O caráter neoliberal de práticas pedagógicas, embutido nas Políticas Educacionais, pretende atingir números que mascaram qualquer possibilidade de qualidade da educação. Na verdade, defende e oferece uma educação vinculada ao mercado, atendendo às exigências de órgãos internacionais, voltada meramente à reprodução técnica de conhecimentos mínimos, não proporcionando o desenvolvimento integral do sujeito, que promova autonomia, capacidade crítica e discernimento (DADICO, 2006).

A hierarquização dos saberes, em que Matemática e Língua Portuguesa ganham centralidade no Programa e nos documentos oficiais, é materializada na discrepância do investimento de tempo no acompanhamento dessas disciplinas em relação às demais atividades. As escolas que aderiram às cinco horas devem oferecer para cada atividade de acompanhamento pedagógico em Língua Portuguesa e Matemática, 2 horas e 30 minutos de duração.

As escolas que aderirem às 15 horas devem oferecer para cada atividade de acompanhamento pedagógico em Língua Portuguesa e Matemática, 4 horas de duração, e as outras 7 horas restantes podem ser distribuídas as atividades de livre escolha. Durante as observações foram observadas diversas aulas de Língua Portuguesa e Matemática, as quais não se diferenciavam das práticas pedagógicas tradicionais, ou seja, as crianças passam mais tempo na escola fazendo as mesmas atividades pedagógicas que há anos não mostram os resultados desejados (SILVA, 2013).

O PNME é considerado uma estratégia educativa que amplia o tempo e espaços escolares, visando a erradicação do fracasso escolar, por isso o programa precisa estar em "sintonia" com o Projeto Político Pedagógico da escola, mesmo que estas atividades sejam executadas por voluntários; a integração fica a cargo do Articulador. O fracasso escolar, segundo o programa, são alunos não alfabetizados; alunos que não têm um bom desempenho em Língua Portuguesa e Matemática, prejudicando os resultados do IDEB; alunos que são reprovados, que não acompanham o ano de ensino de acordo com sua idade e que abandonam a escola.

A obra A produção do Fracasso Escolar: histórias de submissão e rebeldia de Maria Helena Souza Patto (1990), faz uma análise histórica e crítica sobre como a sociedade que, sob a égide de uma falsa cientificidade, foi produzindo concepções preconceituosas sobre o processo de escolarização das crianças das classes mais pobres, herança advinda de uma colonização portuguesa e escravocrata. A autora faz uma relação da construção social do discurso criminológico com os discursos educacionais, destacando que o fracasso escolar é entendido como um processo natural que precisa ser combatido por medidas tomadas pelo Estado e pelas secretarias de educação; nessas medidas encontram-se características da porção mais pobre da classe trabalhadora, que são consideradas como sinais de predisposição ao fracasso escolar.

As Políticas Educacionais buscam respostas para problemas vividos na escola e, as soluções não são neutras, elas representam os elementos de uma realidade e como esta é vista por quem propõe os programas e projetos implementados nas políticas (VIÉGAS; ANGELUCCI, 2006).

Um programa que tem como objetivo erradicar o fracasso escolar, priorizando o atendimento da população mais vulnerável com índice socioeconômico baixo nos mostra que ainda continuamos produzindo o 
fracasso escolar e justificando sua existência na responsabilização da pobreza, pautada por explicações baseadas em déficit e/ou diferenças culturais das crianças e suas famílias (VIÉGAS; ANGELUCCI, 2004).

Tem menino ali que vive muito mal, muito mal. É briga em casa, é pai que bate em mãe, sabe?! [...] Então a casa deles não é boa. Aqueles que estão ali, cada um deles tem mais problema emocional que o outro, muito mesmo (entrevista com a Facilitadora de artesanato) É o menino que tinha muita dificuldade ou é o menino que só dava problema, é o menino que é muito carente... É isso, o que eu sei da seleção é o que eu escuto às vezes. [...]. (Monitora de Português).

O objetivo de erradicar o fracasso escolar está diretamente ligado com o público-alvo do programa, que são os alunos e as escolas de regiões mais vulneráveis, priorizando alunos com maiores dificuldades de aprendizagem e escolas com piores indicadores educacionais.

Tanto o Programa Mais Educação quanto o Novo Mais Educação têm seus objetivos e finalidades semelhantes, priorizam a mesma população e escolas com índice de vulnerabilidade social, considerados, também, como uma política social de combate à fome (CAMPOS, 2003). A diferença é que o Programa Mais Educação foi construído e implementado com a parceria do Ministério do Desenvolvimento Social e Combate à Fome, Ministério do Esporte e o Ministério da Cultura; já o Novo Mais Educação foi instituído somente pelo Ministério da Educação, por mais que mantivesse em seus objetivos problemas sociais de responsabilidade de outros setores, como o combate à fome e a segurança pública.

É possível observar que principalmente depois dos anos 1990, com a forte corrente neoliberal, a escola passou a assumir, a partir de inserção de Políticas Públicas, outras funções para sanar problemas sociais, que são produzidos pelas desigualdades sociais que violam os direitos das classes mais populares para manter a ideologia do sistema capitalista. Essas políticas que se inserem no território das escolas, de caráter assistencialista, não resolvem efetivamente os reais problemas brasileiros, mascarando as situações por meio de políticas compensatórias (SAVIANI, 2004).

De acordo com a fala da Articuladora, o primeiro critério de seleção dos alunos para o Programa era a dificuldade em Português e Matemática; e o segundo critério era os alunos que recebiam Bolsa-Família. Ao questionar a Facilitadora de artesanato sobre qual era o público-alvo do programa, esta responde "Então é assim, sempre foi, né? Primeiro era o pessoal do Bolsa Família, porque eles são mais carentes [sic]". E durante a entrevista com o Monitor de Matemática, este afirma que o programa é benéfico para os alunos, pois diante da realidade de alguns, eles não se alimentam em casa, sendo a escola um lugar que proporciona este alimento.

Essa visão preconceituosa sobre as famílias mais carentes fica nítida quando é perguntado sobre o objetivo do programa:

Para mim o projeto, eu vejo ele como mais tirar a criança do ócio em casa ou na rua e trazer ele para dentro da escola. Para mim, pela experiência que eu tive esse ano, eu vejo ele mais como um programa social do que pedagógico" (entrevista com a Articuladora do PNME).

Sair da rua né! É, por exemplo, sei lá, eu conheço alguns meninos que aprecem aqui de vez em quando, mas que ficam na rua o dia inteiro (entrevista com a Monitora de Língua Portuguesa). 
Só por estar aqui no programa, por estar presente aqui, por não estar na rua, tanto quanto para conteúdo, disciplina, essas coisas aí. (Monitor de Matemática).

Os estudos de Paro e outros autores (1988) e Patto (2007b) mostram que desde o Império Brasileiro propostas de Educação Integral vêm sendo adotadas como solução de crises econômicas e dos problemas de segurança pública, e a educação de qualidade fica em segundo plano ou nem existe. Podemos perceber que subjacente às propostas de Educação em Tempo Integral está presente o enfrentamento dos problemas sociais de abandono de crianças e adolescentes como alternativas de prevenção à delinquência.

Consideramos que o PNME, pelo principal objetivo de ampliação da carga horária escolar, se mostra como uma política social que prioriza o atendimento da classe popular e pretende manter as crianças nas escolas como solução de uma questão de segurança pública. Voltamos a um discurso preconceituoso que relaciona a criminalidade com as classes econômicas menos favorecidas, definindo o pobre como incapaz e propenso à delinquência (PATTO, 1990), ou seja, há uma criminalização da pobreza.

Sabemos que dois dos grandes problemas da implementação de Políticas Públicas são a falta de participação de toda a comunidade escolar, por meio de um processo de discussão democrática das Políticas Educacionais e a falta de estrutura física (SOUZA, 2010), fatores que dificultam bastante a integração do Programa no Projeto Político Pedagógico da escola. De acordo com a entrevista da articuladora, não houve nenhum curso de formação por parte da União, Estado e Município, e nenhuma assembleia e/ou reunião que convocasse a participação dos profissionais da escola e a comunidade para pensarem na implementação do programa. Sendo assim, todas as decisões ficaram a cargo apenas da Articuladora e da Diretora da escola, o que fere uma das diretrizes do Programa.

Essa falta de participação de todos na elaboração das Políticas Educacionais interfere diretamente na sua implementação; os atores encontram dificuldades de integrar o programa ao Projeto Político Pedagógico da escola por não haver muita aceitação pelos professores e demais funcionários, já que não conseguiram entender o objetivo da proposta e nem como podem contribuir para o trabalho pedagógico, vendo o PNME muitas vezes como um problema a mais para a escola. Neste caso, houve muitos desentendimentos entre os atores do programa e demais funcionários da escola, principalmente aumento do número de aluno no contra turno escolar e sobre o uso compartilhado dos espaços físicos e recursos materiais.

O Programa não teve adesão de toda a comunidade escolar e consequentemente, não encontrou espaço na própria escola:

Não vou dizer que é $100 \%$ da escola que valoriza, não é. Eu vejo nos olhos dos professores. Acho que os que menos apoiam são os serviços gerais, limpeza, cantina, elas são as que menos dão valor ao projeto" (entrevista com o Facilitador de Capoeira).

Não, não. Por exemplo, eu não consigo ficar na sala dos professores principalmente à tarde. Os professores olham torto. Eu percebo isso desde o primeiro dia. (Monitora de Língua Portuguesa). 
Até as próprias crianças são hostilizadas por participarem do Programa:

Eu acho que a escola valoriza e não valoriza. Por quê? Até porque tinha a diferença dos alunos do projeto para os alunos da escola, parecia que tinha aluno da escola e aluno do projeto. Até porque a gente ouvia muito "Ah... esses alunos do Mais Educação". E a gente ficava assim, "Não é aluno da escola, não?!”. Parecia que era outra dimensão” (entrevista com Facilitador de Dança) Porque a escola ela esquece que os alunos do Mais Educação é dela. Eles se referem "esses meninos do Mais Educação". [...] 0 que eles querem do programa é o dinheiro. (Facilitadora de Artesanato)

As situações relatadas deixaram claro que o Programa não tem espaço dentro dessa escola, por permanecerem por mais tempo dentro da escola os alunos são vistos como um incômodo e os Monitores e Facilitadores são desautorizados a todo o momento. Olhando para a relação do programa com toda a escola, ficamos com a sensação de que este é externo à instituição e que somente utiliza os seus espaços físicos; é composto por ações sem credibilidade cuja função primordial é ocupar o tempo das crianças, para tirá-las das ruas. Como escreve Patto (1990, p. 343), "O fracasso da escola pública elementar é o resultado inevitável de um sistema educacional congenitamente gerador de obstáculos à realização de seus objetivos."

\section{CONCLUSÃO}

No Brasil, no final do século XX, o debate sobre políticas sociais focalizadas nas classes mais vulneráveis é intensificado na tentativa de elaborar ações que melhore as condições de vida dessa população (OLIVEIRA; DUARTE, 2005; SAVIANI, 2004; SILVA, 2013). E percebemos que muitas destas políticas são implementadas nas escolas, aumentando as suas funções, dificultando que esta compra o papel de socializar o conhecimento historicamente construído pela humanidade.

Após anos de lutas pelos direitos sociais, principalmente depois da constituição de 1988, vemos, no Programa Novo Mais Educação, que as Políticas Educacionais ainda carregam uma visão preconceituosa acerca das camadas mais pobres da sociedade, sendo muitas vezes implantadas para manter um controle social, deixando à mercê a qualidade da educação oferecida para as crianças e jovens do país, sustentando as desigualdades sociais.

É necessário rever as explicações individualizantes do fracasso escolar fazendo uma análise crítica dos mecanismos produtores das dificuldades de aprendizagem e geradores de obstáculos que impedem que a escola exerça sua função. Entendemos que o real fracasso escolar está no ensino que revela equívocos tecnicistas; desinteresses dos governantes para a efetiva formação integral dos alunos; barateamento do custo-aluno; desvalorização dos professores com baixos salários e formação precária; Políticas Educacionais de disputas partidárias e interesses elitizados, destruindo os avanços de governos anteriores; e a interferência de políticas neoliberais, de órgãos internacionais na educação brasileira (PATTO, 1990). 
Apesar dos limites da pesquisa aqui relatados, acreditamos que a Psicologia Escolar pode trazer contribuições importantes para a elaboração e implementação de Políticas Públicas de modo a colaborar com a superação do fracasso que atinge tantas de nossas crianças que ocupam as carteiras das escolas públicas. Elas merecem o melhor que a nossa Educação pode lhes oferecer; como no poema Canção do Remendo e do Casaco, de Bertolt Brecht, elas precisam do casaco inteiro, e não de remendos.

\section{REFERÊNCIAS}

Antunes, M. A. M. Psicologia e Educação no Brasil: Um olhar Histórico-Crítico. In: Meira, M. E. M., Antunes, M. A. M. (Orgs), Psicologia Escolar: Teorias Críticas. pp. 139 - 168. São Paulo: Casa do Psicólogo. 2003.

Antunes, M. A. M. A Psicologia no Brasil: leitura histórica sobre sua constituição. $5^{a}$ ed. São Paulo: EDUC. 2014.

Barbosa, D. R.; Souza, M. P. R. Psicologia Educacional ou Escolar? Eis a questão. Psicologia Escolar e Educacional, 16(1),jan/jun, 163-173. 2012.

Brasil. Portaria $\mathbf{N}^{\mathbf{0}} \mathbf{- 1 . 1 4 5}$, de 10 de outubro de 2016. Institui o Programa de Fomento à Implementação de Escolas em Tempo Integral, criada pela Medida Provisória nº 746, de 22 de setembro de 2016. Disponível em: http://portal.mec.gov.br/docman/outubro-2016-pdf/49121-port1145-11out-pdf/file. Acesso em: 13 fev. 2019.

BRECHT, Bertolt. Teatro Completo. Vol. 4. Rio de Janeiro: Paz e terra, 1990.

Campos, M. M. Educação e políticas de combate à pobreza. Revista Brasileira de Educação. n 24. P. 183-191. Set/out/nov/dez. 2003.

Dadico, L. Terceira Via, Ideologia e Educação. In: Viégas, L de S.; Angelucci, C. B. (orgs.), Políticas Públicas em Educação: Uma análise crítica a partir da Psicologia Escolar. São Paulo: Casa do Psicólogo. 2006.

Digiovanni, A. M. P. Brasil e Cuba: Um estudo comparado sobre políticas públicas de educação básica e as articulações com a psicologia, entre as décadas de 1960 e 1999. (Tese de Doutorado) Universidade Federal de São Paulo, São Paulo. 2016.

Gonçalves, M. G. M. Psicologia e Políticas Públicas: reconhecendo avanços e atualizando desafios. In: Urnau, L. C.; Pacífico, J. M.; Tamboril, M. I. B. (Org.), Psicologia e Políticas Públicas na

Amazônia: Pesquisa, Formação e Atuação. Curitiba, PR: CRV, Porto Velho, RO: EDUFRO. 2014. 
Leclerc, G. de F. E.; Moll, J. Programa Mais Educação: avanços e desafios para uma estratégia indutora da Educação Integral e em tempo integral. Educar em Revista, Curitiba, Brasil, n. 45, pp. 91-110, jul./set. 2012.

Oliveira, D. A.; Duarte, A. Política educacional como política social: uma nova regulação da pobreza. PERSPECTIVA, v. 23, n. 02, p. 279-301, jul./dez. Florianópolis - SC. 2005.

Paro, V. H., Ferretti, C. J., Vianna, C. R.; Souza, D. T. Escola de Tempo Integral - Desafio para o Ensino Público. São Paulo, Cortez: Autores Associados. 1988.

Patto, M. H. S. A produção do fracasso escolar - histórias de submissão e rebeldia. São Paulo: T. A. Queiroz. 1990.

Patto, M. H. S. A Psicologia em questão. In: Patto, M. H. S.; Frayze-Pereira, J. (Orgs.), Pensamento cruel - humanidades e ciências humanas: há lugar para a psicologia? pp. 3-15. São Paulo: Casa do Psicólogo. 2007.

Patto, M. H. S. “Escolas cheias, cadeias vazias” Nota sobre as raízes ideológicas do pensamento educacional brasileiro. Estudos Avançados, 21 (61), pp. 246-266. 2007 b

\section{Saviani, D. Da Nova LDB ao Novo Plano Nacional de Educação: Por Uma Outra Política}

Educacional. 5a ed. Autores Associados: Campinas, SP. 2004.

Saviani, D. Política Educacional no Brasil após a Ditadura Militar. Rev. HISTEDBR On-line.v.18, n.2 [76], p.291-304, abr./jun. Campinas. 2018.

Silva, A. M. C. J. Trabalho docente e educação em tempo integral: um estudo sobre o programa escola integrada e o projeto educação em tempo integral. (Dissertação de Mestrado) - Universidade Federal de Minas Gerais, Belo Horizonte, MG, Brasil. 2013.

Souza, B. P. Orientação à queixa escolar. 1. ed. São Paulo: Casa do Psicólogo. 2007.

Souza, M. P. R. Psicologia Escolar e políticas públicas em Educação: desafios contemporâneos. Em Aberto, Brasília, 23(83), março, pp. 129-149. 2010.

Souza, M. P. R. O movimento da crítica em Psicologia Escolar: Elementos para a compreensão da trajetória de uma área de atuação profissional. In: Souza, M. P. R.; Silva, S. M. C.; Yamamoto, K. Atuação do psicólogo na Educação Básica: concepções, práticas e desafios. Uberlândia: EDUFU. 2014. 
Viégas, L. de S.; Angelucci, C. B. (orgs.), Políticas Públicas em Educação: Uma análise crítica a partir da Psicologia Escolar. São Paulo: Casa do Psicólogo. 2006.

Zibetti, M. L. T., Pacífico, J. M.; Tamboril, M. I. B. A educação como direito: considerações sobre políticas educacionais. In: Campos, H. R., Souza, M. P. R.; Facci, M. G. D. (Org.), Psicologia e

Políticas Educacionais. Natal, RN: EDUFRN. 2016. 
1 Mestre em Processos Psicossociais em Saúde e Educação, pelo Instituto de Psicologia da Universidade Federal de Uberlândia (2019); Graduada em Psicologia pela Universidade Federal de Uberlândia (2016), com formação nas ênfases de Psicologia Escolar e Educacional e Psicologia Clínica. E-mail: barbaramaria.cs5@gmail.com

2 Doutora em Educação pela Universidade Estadual de Campinas (2002); Mestre em Educação pela Universidade Estadual de Campinas (1993); Graduada em Psicologia pela Pontifícia Universidade Católica de Campinas (1990); Pós-doutorado na USP, no Programa de Pós Graduação em Psicologia Escolar e do Desenvolvimento Humano (2007); Professora Titular da Universidade Federal de Uberlândia, ministra aulas na graduação e no mestrado do Instituto de Psicologia e supervisiona estágio na área de Psicologia Escolar; 1a. Secretária (gestão 2020-2022); Editora da Revista Psicologia Escolar e Educacional; Vice-coordenadora do GT Psicologia e Políticas Educacionais da Associação Nacional de Pesquisa e Pós-Graduação em Psicologia - ANPEPP; Temas de interesse: psicologia escolar, formação e atuação do psicólogo escolar e arte; Foi coordenadora do Curso de Graduação em Psicologia e coordenadora do Programa de Pós-graduação em Psicologia; Ocupou o cargo de Presidente Atual da Associação Brasileira de Psicologia Escolar e Educacional (ABRAPEE) (gestão 2014-2016).

E-mail: silvia@ufu.br

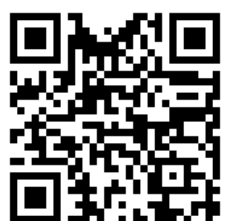

A autenticidade desse artigo pode ser conferida no site https://periodicos. set.edu.br

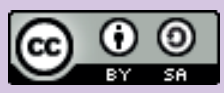

Este artigo é licenciado na modalidade acesso abertosob a Atribuição-Compartilhalgual CC BY-SA

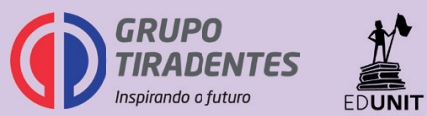

